\title{
Molecular Method to Diagnosis of some Strongylide Nematode of goats in Nyala Area South Darfur State- Sudan
}

\author{
Salma.A.Hassan ${ }^{1}$. Abbaker. A. Mohammed ${ }^{2}$, Fayza.A.Omer ${ }^{3}$ \\ ${ }^{1}$ Small ruminants development and research center- Faculty of veterinary science, University of Nyala-Sudan. \\ ${ }^{2}$ Departments of preventive medicine and public health Faculty of veterinary science, University of Nyala \\ Sudan. \\ ${ }^{3}$ Department of pathology and animal diseases diagnosis-Central veterinary research laboratory (CVRL) \\ Sudan-Soba
}

\begin{abstract}
A total of 100 positive faecal samples were examined using floatation technique to detect strongylide eggs, were confirmed by PCR technique, faecal samples were storage by frozen in $-20^{\circ} \mathrm{C}$ and DNA extraction by using phenol/chloroform/isoamylalcohol protocol. PCR leading to amplify the region of the second internal transcribed spacer (ITS-2) of nuclear ribosomal DNA ( $r$ DNA) of strongylide species, amplification by three different primers in separate reactions, in each reaction used species specific primer forward and a universal reverse primer to srongylide species NC2. Haemonchus contortus, Trichostrongylus spp and Oesophagostomum columbianum prevalence rates were recorded as 47(47\%), 4(4\%) and (0\%) respectively, Most commonly, small ruminants are affected by multiple strongylide nematodes, mixed infection between Haemonchus contortus and Trichostrongylus spp was recorded 3(3\%)
\end{abstract}

Keyword: Strongylide, PCR, ITS-2, NC2, goats, Sudan.

\section{Introduction}

Parasitic worms of livestock cause diseases of major socioeconomic impact worldwide (Roeber et.al 2013), goats play an important role in the economy of rural communities where they are commonly raised by poor families and farmers for livelihood (Bushara, et.al, 2011). Gastrointestinal Nematodes (GINs) of goats remain one of the main constraints to goats production; they cause reduction of animal productivity by reduction of body weight and milk yield (Soulsby.1986) and Amarante and Amarante (2016), especially Haemoncus contortus, Trichostrongylus spp and Oesophagostomum columbianam are most common, pathogenic and economic impacts of small ruminants (Bowman, 2009). (GINs) have a worldwide distribution and more commonly affect goats in the tropical and sub- tropical regions of the world (Soulsby, 1986; Kusiluka and kambarage, 1996). Usually diagnosis of (GINs) depends on microscopic technique to detect eggs or larvae on the animal faeces (Zajac and Conby2006). Problem facing faecal egg count as diagnostic method for the fact that many parasites lay quite similar eggs which are very difficult to differentiate from one another, but differentiation and identification of the third stage larvae can be carried out by faecal culture (Hansen and Perry, 1994). Molecular techniques such as PCR and DNA sequencing have enabled the accurate identification of parasites (Gasser, et.al, 1993). These advanced techniques are highly sensitive, providing highly accurate identification of strongylide up to species level(Tan,et.al,2014) by using genomic DNA isolation from strongylide eggs from fresh or frozen faecal samples(Bott,et.al,2009.; Tan,et.al,2014). This study was conducted to identification and differentiation of some strongylide nematode species using PCR technique using DNA extracted from faecal samples.

\section{Materials and methods}

A total of 100 faecal samples positive for strongylide by flotation technique was stored by freezing at $20^{\circ} \mathrm{C}$ for extracting DNA. For DNA extraction, $1 \mathrm{~g}$ stool, frozen at $-20^{\circ} \mathrm{C}$, diluted in $10 \mathrm{ml}$ of lysis buffer (TrisHCL, $0.5 \mathrm{M}$; EDTA, $20 \mathrm{mM}$; NaCl, $10 \mathrm{mM}$; SDS, \%0.1; pH 9.0) (TEN-9) in $50 \mathrm{ml}$ tube. After vortexing for 5 minutes, samples are then homogenized by shaking for 10 minutes. Samples were then diluted again $(1: 2)$ with $10 \mathrm{ml}$ lysis buffer and homogenized for 5 minutes. Particulate materials were removed by centrifugation at 4500 $\times \mathrm{g}$ for 10 minutes. After transferring the supernatant to a new tube, approximately $10 \mathrm{ml}$ of supernatant, DNA was precipitated by adding $5 \mathrm{ml}$ ammonium acetate $7.5 \mathrm{M}$ (half of the sample volume) and $25 \mathrm{ml}$ of ice-cold ethanol $96-100 \%$ (twice the sample volume). Then incubation at $-20^{\circ} \mathrm{C}$ for $20-30$ minutes will render a better precipitation. DNA was collected following centrifugation at $4500 \times \mathrm{g}$ for 15 minutes at room temperature. In this step, precipitated DNA is coloured and contains the bile salts. The DNA pellet was re-suspended in $600 \mu 1$ of TE $(\mathrm{pH} 8)$ and incubated at $65^{\circ} \mathrm{C}$ for 15 minutes. Then, DNA was extracted organically and also purified using conventional single step phenol/chloroform/isoamylalcohol protocol. Phenols will dissolve the colorful materials. After isopropanol precipitation, the colourful DNA pellet was collected and dissolved in $300 \mu 1$ of 
Tris-EDTA buffer following an overnight incubation at $37^{\circ} \mathrm{C}$. This method was described by Machiels et al. (2000) and Abbaszadegan et al. (2007). PCR causing amplification of the region of the second internal transcribed spacer (ITS-2) of nuclear ribosomal DNA (rDNA) of strongylide species. Amplification by three different primers in separate reactions, in each reaction species specific primer forward and universal reverse primer to srongylide species NC2 (Bott et.al, 2009) are used.

PCR was carried out in the Bio-rad MyCyler ${ }^{\mathrm{TM}}$ Thermal Cycler by using initial denaturation at $94{ }^{\circ} \mathrm{C}$ for 5 minutes, followed by 35 cycles of $94{ }^{\circ} \mathrm{C}$ for $30 \mathrm{~s}$ (denaturation), 55-C for $30 \mathrm{~s}$ (annealing) and 72 -C for 30 s (extension), followed by a final extension at $72{ }^{\circ} \mathrm{C}$ for 7 minutes. (Bott, et.al., 2009 and Tan.et.al., 2014).

To verify PCR amplification $5 \mu \mathrm{l}$ of PCR product was loaded in gel containing $1.5 \%$ agarose dissolved in $1 \mathrm{x}$ TBE (65mM Tris-HCL,27Mmboric acid,1m M EDTA,PH 9). Staining with $5 \mu 1$ of Ethidium bromide solution at voltage 100 volts for 30 minutes in $1 \mathrm{x}$ TBE buffer, $3 \mu$ of $100 \mathrm{~Pb}$ DNA ladder was run alone with amplicons. Species specific primer forward and a universal reverse primer to strongylide species table.(1)

\begin{tabular}{|c|c|c|c|c|}
\hline Species & Primer & Forward sequence & Reverse sequence & Amplicon length (pb) \\
\hline Haemonchus contortus & HAE & CAAATGGCATTTGTCTTTTAG & \multirow[t]{3}{*}{ TTAGTTTCTTTTCCTCCGCT } & 265 \\
\hline Trichostrongylus spp & TRI & TCGAATGGTCATTGTCAA & & $267-268$ \\
\hline $\begin{array}{l}\text { Oesophagostomum } \\
\text { columbianum }\end{array}$ & $\mathrm{OEC}$ & TGTCGAACGATGCTTGCT & & 251 \\
\hline
\end{tabular}

\section{Statistical analysis:}

Data analyzed using Microsoft Excel 2007.

\section{Results}

PCR reaction was optimized for the amplification of DNA of $\mathrm{H}$. contortus Trichostrongylus sp and Oesophagostomum columbianam using a specific oligonucleotide primer located in the ITS-2 of rDNA. Out of 100 samples examined, Haemonchus contortus, Trichostrongylus spp and Oesophagostomum columbianum prevalence rates were recorded as 47(47\%), 4(4\%) and (0\%) respectively, Most commonly, small ruminants are affected by multiple strongylide nematodes, mixed infection between Haemonchus contortus and Trichostrongylus spp was recorded 3(3\%) as shown as in table (2), figure (1) and (2).

Table (2) Prevalence of Haemonchus contortus, Trichostrongylus sp and Oesophagostomum columbianam of goats by PCR technique in the study area

\begin{tabular}{|l|l|l|}
\hline Species No. Samples examined & No.positive \\
\hline Haemonchus contortus & 100 & $47(47 \%)$ \\
\hline Trichostrongylus sp & 100 & $4(4 \%)$ \\
\hline Oesophagostomum columbianam. & 100 & $(0 \%)$ \\
\hline $\begin{array}{l}\text { Mixed infection H.contortus and } \\
\text { Trichostrongylus spp }\end{array}$ & 100 & $3(3 \%)$ \\
\hline
\end{tabular}

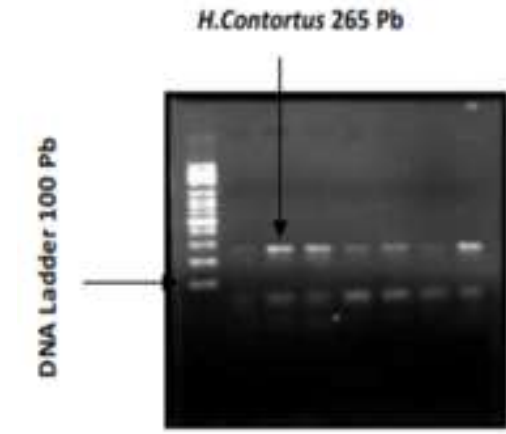

Figure (1): Agarose gel electrophoresis $(1.5 \%)$ amolification of $H$. contortus DNA

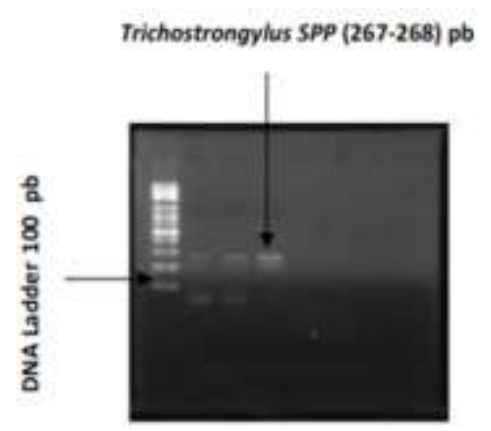

Figure (2) gel electrophoresis $(1.5 \%)$ amplification of Trichostrongyius sp DNA band size (267-268 Pb)

\section{Discussion}

Specific diagnosis of nematode infection has major implication for monitoring of drug resistance in nematode population and can underpin studies of the biology, ecology and epidemiology of strongylid (Roeber et.al 2011). This investigation revealed that the study area conspicuously lack molecular data focusing on strongylide nematode parasites of small ruminants. 
In the present study the positive faecal samples which were diagnosed for strongylide nematodes by using McMaster Technique were further tested by PCR technique. Thus (47\%) of 100 samples were recorded positive for Haemonchus contortus. This result was different from that of (Anwar et.al 2014) who recorded (66\%) of 44 a positive diagnosis of samples, and is smallest than that reported by Tan et.al (2014) and Roeber et.al (2011). Furthermore the present results trichostrongylus spp are also smallest. Those shown by Tan et.al (2014) for the same parasite which recorded as (79.8\%) of 99 samples. However no amplification with Oesophagostomum colmbianum was recorded in the present study. Occassionally, small ruminants are affected by multiple strongylide nematodes (Zajac 2006), hence mixed infection by Haemonchus contortus and Trichostrongylus spp (3\%) was recorded in this study. This result was in favorable with that of Tan et.al (2014) who reported (1.9) in one study but was strikingly different for the (45.2\%) shown by them partially for another mixed infection.

Contrary to our general results Sweeny et.al (2011), observed very similar results for McMaster and PCR techniques for genomic DNA extracting directly from faeces, it is seen that such variations may results from differences in techniques and the biological materials. These are known to cause problems when PCR is used as diagnostic methods for the probable existence of impurities that inhibit PCR amplification as was suggested by (Abbaszadegan et.al, 2007).

\section{Conclusion}

In the present study demonstrated that flotation technique revealed higher strongylide infection result, furthermore PCR was identification genera of strongylide infection, using phenol/chloroform/isoamylalcohol protocol in faecal DNA extraction leading to PCR inhibitor. In addition, the study concluded that the Haemonchus contortus is prevalent in goats in the study area.

\section{Acknowledgments}

Thanks for Tropical Medicine Research Institute- National Research Center - Department of epidemiology members, and special thanks to Mr.Salaheldein Gumaa Elzaki for support and facilitate this work.

\section{References}

[1]. Abbaszadegan.RM, Velayati.A. and Tavasoli.A (2007). Rapid DNA Extraction Protocol from Stool, Suitable for Molecular Genetic Diagnosis of Colon Cancer. Iranian Biomedical Journal 11, 3: 203-208.

[2]. Amarante, AFT and Amarante, MRV (2016). Advances in the diagnosis of the gastrointestinal nematodes infections in ruminants. Braz. J. Vet. Res. Anim. Sci. Saopaulo, 53 (2):127-137.

[3]. Anwar S, Lateef M, Maqbool A, Anjum.AA.Rashid.IM, Akber H. and Wasim H (2014). Specificity of different diagnostic technique for ovine Haemonchosis through coprological examination. Sci .Int (Lahore), 26, 1: 249-251.

[4]. Bott.N J, Campbell.E B, Beveridge I, Chilton N B, Ress D, Hunt. PW.and Gasser. RB (2009). A combined microscopic-molecular method for the diagnosis of strongylid infections in sheep: International Journal for Parasitology 39: 1277-1287

[5]. Bowman DD. (2009) Georgis parasitology for veterinarians $10^{\text {th }}$ edition, sanders, St. Louis, Missouri. 63043 pp 499.

[6]. Bushara I, Elemam.M B, Abdelhadi OMA, Idris.AO. and Abu Nikhala. AM (2011). American-Eurasian .J.Agric and Environ.Sci; 10, 4: 515-518.

[7]. Gasser.RB, Chilton.NB, Hoste H and Beveridge I. (1993). Rapid sequencing of rDNA from single worms and eggs of parasitic helminthes. Nucleic Acids Research,Vol. 21, 10: 2525-2526

[8]. Hansen J. and Perry B (1994). Epidemiology, diagnosis and control of helmith parasites of ruminants. A hand book. International laboratory of research in animal diseases. Nairobi, Kenya. pp 170.

[9]. Kusiluka L. and Kambarage D. (1996) .Diseases of small ruminants in sub- Saharan Africa: A hand book.VETAID Center for TropicalVeterinary Medicine. Scotland

[10]. Machiels. BM, Ruers T, Lindhout M, Hardy K, Halvaty T, Bang. DD, Somers. VA, Baeten C, Von Meyenfeldt M. andThunnissen. FB (2000). New protocol of DNA extraction of stool. Biotechniques 28:286-290.

[11]. Roeber F, Jex.RA, and Gasser, BR (2013). Impact of gastrointestinal parasitic nematodes of sheep, and the role of advanced molecular tools for exploring epidemiology and drug resistance- an Australian perspective. Parasite and Vectors, 6:153.

[12]. Roeber F, Jex RA, Cambell. JDA, Chambell.EB, Anderson.AG. and Gasser.BR. (2011). Evaluation and application of molecular method to assess the composition of strongylid nematode populations in sheep with naturally acquired infections. Genetics and Evolution 11: 849-854.

[13]. Soulsby E J L. (1986). Helminthes, Arthropods and Protozoa of Domesticated Animals. $7^{\text {th }}$ edition, Bailliere Tindall, London. 809 pp.

[14]. Sweeny. J P A, Robertson. I D, Ryan. U M, Jacobson C. and Woodgate. RG. (2011). Comparison of molecular and McMaster techniques to confirm the presence of naturally acquired strongylid nematode infections in sheep. Molecular and Biochemical Parasitology, 180: 62-67.

[15]. Tan. TK, panchad.C low, L.V Lee, L.V, Ngui R, Sharma. SKR. and Lim AL.Y (2014):Co-infection of Haemonchus contortus and Trichostrongylus spp among livestock in Malaysia as reveled by amplification and sequencing of internal transcribed spacer $\Pi$ DNA region, MBC veterinary research, 10:38

[16]. Zajac. AM and Conboy. G A (2006). Veterinary Clinical parasitology, $7^{\text {th }}$ edition, Blackwell Publishing Professional, USA. ISBN13:978-0-8138-1734-7.

[17]. Zajac, A. M. (2006). Gastrointestinal nematodes of small ruminants: life cycle, anthelmintics, and diagnosis. Vet. Clin. North Am. Food Anim. Pract 22: 181-182. 